\title{
Variations of the snow physical parameters and their effects on albedo in Sapporo, Japan
}

\author{
Teruo AOKI, ${ }^{1}$ Hiroki MOTOYOSHI, ${ }^{2}$ Yuji KODAMA, ${ }^{3}$ \\ Teppei J. YASUNARI, ${ }^{3}$ Konosuke SUGIURA ${ }^{4}$ \\ ${ }^{1}$ Meteorological Research Institute, 1-1 Nagamine, Tsukuba 305-0052, Japan \\ E-mail: teaoki@mri-jma.go.jp \\ ${ }^{2}$ The Graduate University for Advanced Studies, Kaga 1-9-10, Itabashi-ku, Tokyo 173-8515, Japan \\ ${ }^{3}$ Hokkaido University, Kita-19, Nishi-8, Kita-ku, Sapporo 060-0819, Japan \\ ${ }^{4}$ Institute of Observational Research for Global Change, Japan Agency for Marine-Earth Science \\ and Technology, 2-15 Natsushima-cho, Yokosuka 237-0061, Japan
}

\begin{abstract}
Continuous measurements of the radiation budget and meteorological components, along with frequent snow-pit work, were performed in Sapporo, Hokkaido, Japan, during two winters from 2003 to 2005. The measured relationships between broadband albedos and the mass concentration of snow impurities were compared with theoretically predicted relationships calculated using a radiative transfer model for the atmosphere-snow system in which different types (in light absorption) of impurity models based on mineral dust and soot were assumed. The result suggests that the snow in Sapporo was contaminated not only with mineral dust but also with more absorptive soot. A comparison of the measured relationships between broadband albedos and snow grain size for two different layers with the theoretically predicted relationships revealed that the visible albedo contains information about the snow grain size in deeper snow layers $(10 \mathrm{~cm})$, and the near-infrared albedo contains only surface information. This is due to the difference in penetration depth of solar radiation into snow between the visible and the near-infrared wavelengths.
\end{abstract}

\section{INTRODUCTION}

Snow albedo is an important parameter in controlling the radiation budget in the cryosphere. The mechanism of icealbedo feedback is strongly related to the snow albedo process. In the case of optically deep snow, the visible and near-infrared albedos mainly depend on the respective snow impurities (water-insoluble solid particles) and snow grain size as factors of snow itself (Warren and Wiscombe, 1980; Wiscombe and Warren, 1980). The highest albedo is expected for new snow without impurities. However, once the snow is contaminated with absorptive impurities for light, the visible albedo decreases preferentially. Solar energy absorbed by snow in the visible wavelengths increases the snow temperature and thus increases the snow grain size through crystal metamorphism. The increase in snow grain size reduces the near-infrared albedo and also reduces the visible albedo of snow contaminated with impurities, because the degree of visible albedo reduction due to snow impurities depends on snow grain size also (Warren and Wiscombe, 1980). The overall process of this albedo reduction is in essence a snow ageing effect. The theoretical understanding of such a snow albedo process has been advanced with radiative transfer models (Warren, 1982; Aoki and others, 1999). From those investigations, a snowfall is only one process to increase snow albedo, along with the effects of solar zenith angle and cloud cover (Aoki and others, 1999).

The source of snow impurities affecting snow albedo is the atmospheric absorptive aerosols (Warren and Wiscombe, 1980; Aoki and others, 2000). Hansen and Nazarenko (2004) recently demonstrated that long-range transport of strongly absorptive aerosols such as black carbon could be a cause of snow albedo reduction. Possible snow albedo reduction by black carbon contamination was revealed by radiation measurements on the snow surface at Barrow, Alaska, USA, (Aoki and others, 1998) and in Japanese urban areas (Motoyoshi and others, 2005). Koch and Hansen (2005) showed that the predominant sources of Arctic soot today are in south Asia (industrial and biofuel emissions and biomass burning). Natural insoluble aerosols such as mineral dust are also principal snow impurities during the melt season due to the effect of Asian dust. The process of aerosol deposition on the snow surface could accelerate snowmelting and thus global warming.

Roesch and others (2004) compared surface albedos at spatial and spectral resolution retrieved from moderateresolution imaging spectroradiometer (MODIS) data with those simulated with the general circulation model (GCM) and found that neglecting albedo variations leads to significant errors in the simulated regional climate and horizontal fluxes, mainly in mountainous and/or snow-covered regions. Nolin and Frei (2001) calculated the energy budget on the snow surface using snow albedo parameterization as a function of snow grain size and reported that the variable albedo was significantly more realistic and representative than the constant albedo value. To accurately simulate future climate conditions on the Earth, a physically based snow albedo model that calculates the effects of the snow physical parameters on the albedo employed in the landsurface models (LSMs) or GCMs is necessary. There are very few physically based snow albedo models. Marshall and Oglesby (1994) developed the snow albedo parameterization in the GCM, taking into account the effects of snow grain size and snow impurities, and Flanner and Zender (2006) developed a theoretical model to predict the effects of snow ageing (snow grain size) and albedo evolution for dry snow. However, snow sub-models that estimate albedo 
empirically are mainly used in LSMs or GCMs at present. To develop a physically based snow albedo model, the effects of snow physical parameters on snow albedo should be investigated from field measurements taken under different snow conditions.

The effects of snow impurities and snow grain size on broadband albedos were identified from long-term radiation budget measurements on the snow surface and snow-pit work at Kitami, in a dry snow area of Japan (Aoki and others, 2003), and at Shinjo, in a wet snow area of Japan (Motoyoshi and others, 2005). Since 2003, we have carried out similar observations with more detailed snow-pit work for a vertical profile of snow grain size and aerosol monitoring in Sapporo, Japan. The snow conditions (depth and wetness) in Sapporo are midway between those of Kitami and Shinjo. Using these data during the winter in 2003/04, Aoki and others (2006) showed the effects of atmospheric aerosol deposition to the snow surface on albedo reduction, especially for the heavy Asian dust event in March 2004. For the present study, we analyzed data from Sapporo taken during two winters in 2003-05 and investigated variations of snow physical parameters and their effects on albedo.

\section{OBSERVATION CONDITIONS, INSTRUMENTS AND ANALYSES}

The observation site was the meteorological observation field $\left(43^{\circ} 04^{\prime} 56^{\prime \prime} \mathrm{N}, 141^{\circ} 20^{\prime} 30^{\prime \prime} \mathrm{E} ; 15 \mathrm{~m}\right.$ a.s.l.) of the Institute of Low Temperature Science, Hokkaido University, located in an urban area of Sapporo. The ground condition at this site was flat grassland. Field measurements of the radiation budget and basic meteorological components made with an automatic weather station have been performed since September 2003 and continue at present (June 2006). For this study we analyzed data taken during the two winters (November-April) in 2003-05.

In the radiation budget observation, upward and downward radiant flux densities were measured with pyranometers (CM-21, Kipp \& Zonen) in the shortwave region $(\lambda=0.305-2.8 \mu \mathrm{m})$, with an RG715 cut-off filter dome in the near-infrared region $(\lambda=0.715-2.8 \mu \mathrm{m})$ and with a pyrgeometer (CG-4, Kipp \& Zonen) in the longwave region $(\lambda=4.5-42 \mu \mathrm{m})$. Flux densities in the visible region $(\lambda=0.305-0.715 \mu \mathrm{m})$ were calculated as the difference between the flux densities for the former two regions of the solar spectrum. The reason we measured the radiation for two spectral regions in the shortwave spectrum is that the major LSMs and GCMs divide the shortwave spectrum into visible and near-infrared regions in their radiation schemes. Each radiation component was sampled every $10 \mathrm{~s}$, and $1 \mathrm{~min}$ averaged values were stored in a data logger. The air temperature $\left(T_{\mathrm{a}}\right)$ was measured with a platinum resistance thermometer, and snow depth $\left(d_{\mathrm{s}}\right)$ with a supersonic snow gauge, every minute. For analyses of albedos and meteorological components, $30 \mathrm{~min}$ averaged values from 1131 to $1200 \mathrm{~h} \mathrm{LT}$ (local time), including the local solar noon, were used to keep the observational conditions uniform, except for solar zenith angle $\left(\theta_{0}\right)$. The snow surface temperature $\left(T_{\mathrm{s}}\right)$ was calculated from the measured upward longwave radiation using equation (1) in Aoki and others (2003) with a snow emissivity of 0.97 . Some data for $T_{\mathrm{a}}, T_{\mathrm{s}}$ and $d_{\mathrm{s}}$ are missing due to a malfunction of a data logger. The missing periods are November 2003 to 13 March 2004 and 1519 April 2005 for $T_{a}$, all of the first winter and 15-19 April
2005 for $T_{\mathrm{s}}$, and all of the first winter and 18 March-13 April 2005 for $d_{\mathrm{s}}$. Instead of the missing $T_{\mathrm{a}}$, air-temperature data measured by the Sapporo District Meteorological Observatory (SDMO; $43^{\circ} 03^{\prime} 30^{\prime \prime} \mathrm{N}, 141^{\circ} 19^{\prime} 42^{\prime \prime} \mathrm{E}$; $17 \mathrm{~m}$ a.s.l.), located $3 \mathrm{~km}$ south-southwest of our site, were used. There were no alternative data for the missing $T_{\mathrm{s}}$. The values of $d_{\mathrm{s}}$ were determined from snow-pit work (twice a week), and the values for the days without snow-pit work were interpolated using the data from SDMO.

Snow-pit work was performed approximately twice a week to determine the snow types, temperature and density for all snow layers, as well as the snow grain size for each snow layer from the surface to a depth, $d$, of $10 \mathrm{~cm}$. Snow samplings were taken for two snow layers $(d=0-2 \mathrm{~cm}$ and $0-10 \mathrm{~cm})$ to measure the mass concentration of snow impurities. The time of day for the snow-pit work was almost always around $1100 \mathrm{hLT}$. The collected snow samples were filtered using Nuclepore filters, and the mass concentration of snow impurities was estimated by weighing the Nuclepore filters with a balance.

\section{RESULTS AND DISCUSSION}

\section{Variations of snow physical parameters}

Figure 1 presents the observed results for snow types obtained from the snow-pit work. The maximum snow depth was just above $1 \mathrm{~m}$ in both winters. The yearly peaks of the daily maximum snow depth and yearly maximum snow depth averaged over the past 30 years (1971-2000), as measured by SDMO, were $75 \mathrm{~cm}$ (around 20 February) and $101 \mathrm{~cm}$ respectively. Comparing our results with these records, the snow accumulation conditions at our observation site during the two winters did not deviate much from average conditions. In Figure 1, the measured snow depth increases until the end of February or the beginning of March, and decreases in March and April. We refer to the former period as the 'accumulation season' and the latter period as the 'melt season'. Observed snow types in the upper layers in the accumulation season consisted of new snow, lightly compacted snow and compacted snow, while the lower layers consisted of granular snow. The formation of a lower granular snow layer is due to upward soil heat flux from the underlying ground. The measured ground temperatures were almost $0^{\circ} \mathrm{C}$ except at the beginning of the snow season. Granular snow was also sometimes observed at the top layer even in the accumulation season. Internal snow types observed in Sapporo in the accumulation season were quite different from those observed at Kitami $\left(43^{\circ} 49^{\prime} 21^{\prime \prime} \mathrm{N}\right.$, $143^{\circ} 54^{\prime} 13^{\prime \prime} \mathrm{E} ; 85 \mathrm{~m}$ a.s.l.) by Aoki and others (2003), where faceted crystals (solid-type depth hoar) and depth hoar were observed in the middle and lower layers of the snowpack. Although Sapporo and Kitami are located at similar latitudes and at low altitudes, with a distance of $220 \mathrm{~km}$ between the two sites in Hokkaido, the internal snow types show a significant contrast in both snowpacks. At Kitami, the locational characteristics of cold temperatures and less snow cover produce a snow temparature gradient conducive to the formation of depth hoar (Hirashima and others, 2004), while snow temperature gradient in Sapporo was small due to high air temperature and deep snow.

The melt season in the 2003/04 winter began 2 weeks earlier than in the 2004/05 winter. Significant submerged snow layers were observed at the bottom layers in the 

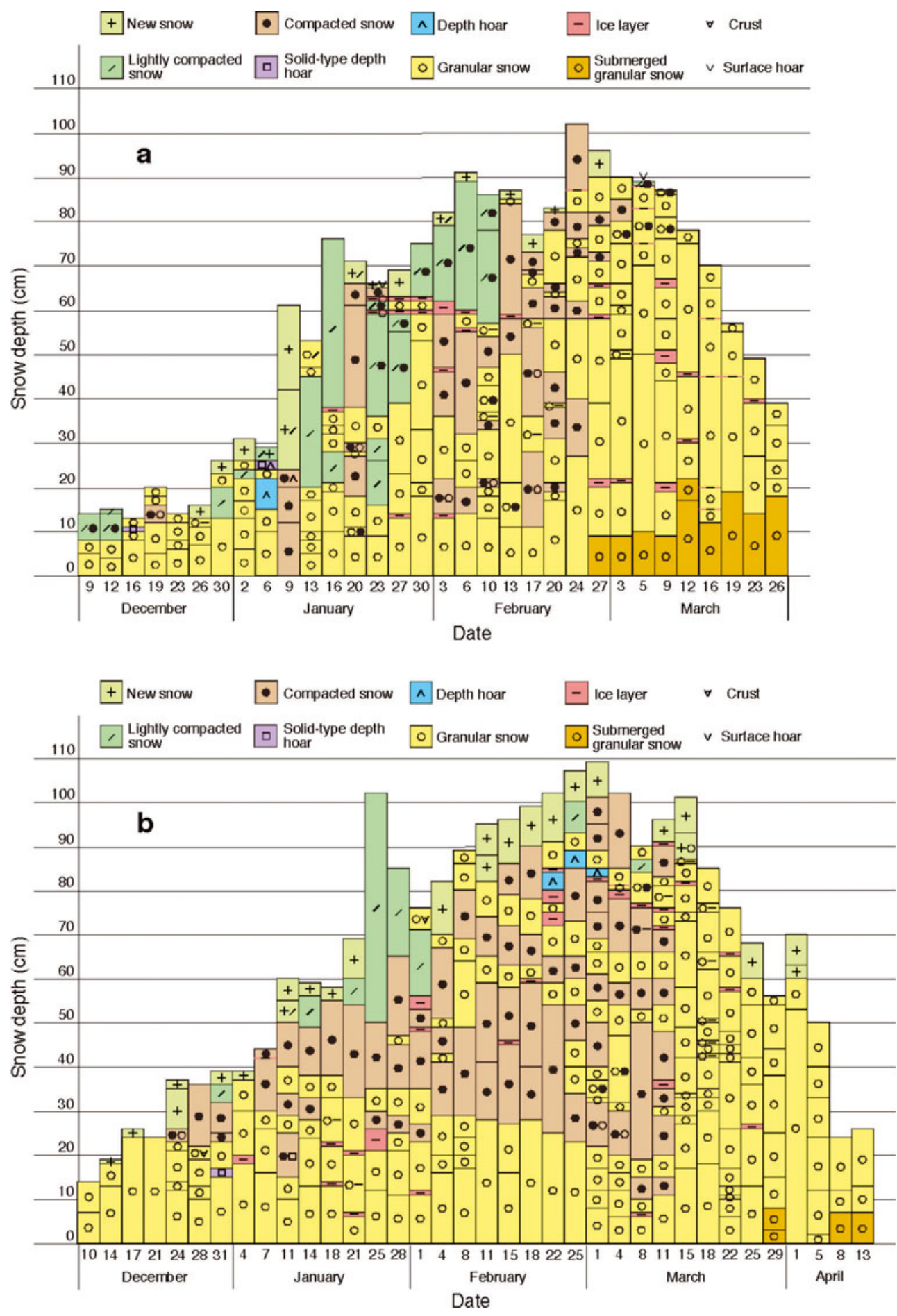

Fig. 1. Snow-pit work results showing the vertical profiles of snow types during the winters of 2003/04 (a) and 2004/05 (b) in Sapporo.

snowpack during the melt season in the first year (Fig. 1a). The snow disappearance date in the first winter was 2 weeks earlier than in the second winter. The difference in the onset of the melt season between the two years was caused by an air-temperature difference in February (Fig. 2). Following that, temperatures in the 2003/04 winter were higher than in the 2004/05 winter, and thus rapid melting along with submerged snow layers occurred. $T_{\mathrm{s}}$ was measured only during the 2004/05 winter (Fig. 2b). When $T_{\mathrm{s}}$ increased up to $0^{\circ} \mathrm{C}$, granular snow was observed.

Figure 3 presents the snow grain size and mass concentration of snow impurities for two different snow layers, measured from snow-pit work and snow sampling. The measured snow grain size is defined in the same way as $r_{2}$ in Aoki and others (2003), namely one-half the branch width of dendrites or one-half the dimension of the narrower portion of broken crystals. This dimension corresponds with the optically equivalent snow grain radius (Aoki and others, 1998, 2000). Measured values of snow grain size at the snow surface were generally smaller than those for $d=0-10 \mathrm{~cm}$. This is because the snow grain size at lower positions (older snow) has increased compared with surface snow due to crystal metamorphism, such as a sintering or a melting for a longer time. These values were on the order of $1.0 \mathrm{~mm}$ for granular snow and were one order of magnitude smaller for new snow and (lightly) compacted snow. The 

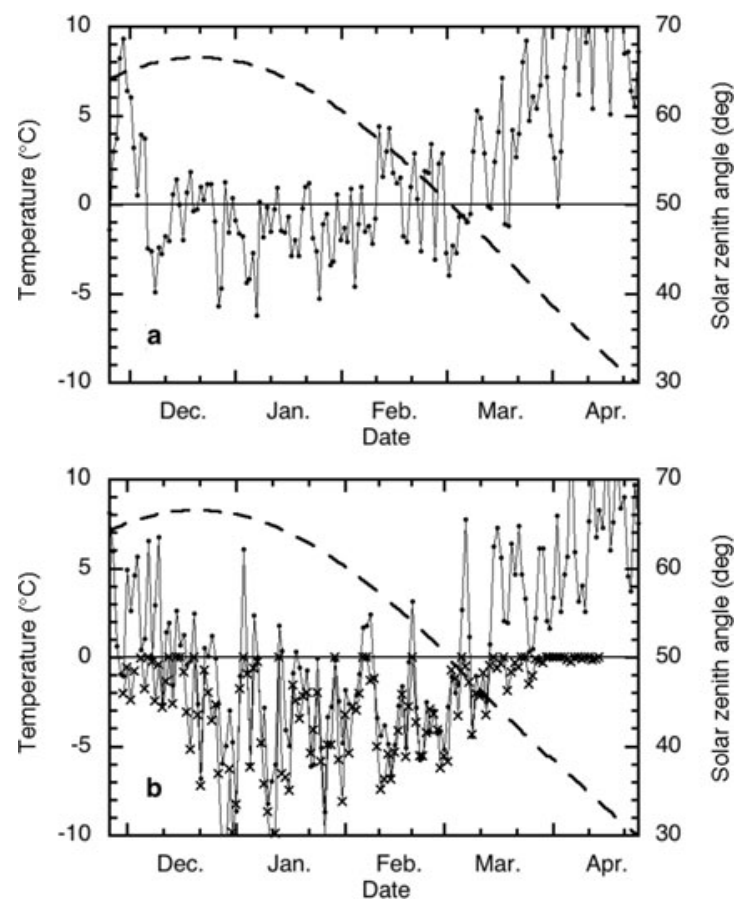

Fig. 2. Air temperature, $T_{\mathrm{a}}$ (solid line with dots), and snow surface temperature, $T_{\mathrm{s}}$ (solid line with crosses), averaged for 1131$1200 \mathrm{~h} \mathrm{LT}$, and solar zenith angle, $\theta_{0}$ (dashed curve), at $1145 \mathrm{~h} \mathrm{LT}$ during the winters of 2003/04 (a) and 2004/05 (b). Due to a datalogger malfunction, some data are missing: for November 2003 to 13 March 2004 and 15-19 April 2005 for $T_{a}$, and during the first winter and 15-19 April 2005 for $T_{\mathrm{s}}$. Air temperatures at $1200 \mathrm{~h} \mathrm{LT}$ measured by SDMO are plotted instead of the missing $T_{a}$, while there were no alternative data for $T_{\mathrm{s}}$.

latter size is the same order as the mean convex radius $(0.1-$ $0.2 \mathrm{~mm}$ ) measured at many different sites in Antarctica (Gay and others, 2002) and is larger than the effective radius (area-weighted mean radius) $(0.024 \mathrm{~mm})$ measured at the South Pole (Walden and others, 2003).

Values of snow impurities for the top layer $(d=0-2 \mathrm{~cm})$ were generally higher than those for $d=0-10 \mathrm{~cm}$ because the snow impurities are supplied by the depositions of atmospheric aerosols, as suggested by Aoki and others (2000). For new snow and (lightly) compacted snow during the accumulation season, concentrations in the $d=0-2 \mathrm{~cm}$ and $d=0-10 \mathrm{~cm}$ layers were $2-8$ and $0.7-8 \mathrm{ppmw}$, respectively. They increased remarkably during the melt season, especially for granular snow, and sometimes exceeded 100 ppmw. The abrupt rise in March 2004 was due to the heavy Asian dust event on 11-12 March (Aoki and others, 2006).

Figure 4 presents broadband albedos averaged for 1131$1200 \mathrm{hLT}$ (close to the local solar noon) for the visible, nearinfrared and shortwave regions, along with the snow depth. Each albedo remained stable during the accumulation season compared with the melt season. The difference in albedo between accumulation and melt seasons corresponds to the difference in snow types between those seasons. During the accumulation season, the short-term variation of the near-infrared albedo exceeded that of the visible albedo. Aoki and others (2006) explained, based on the data from the 2003/04 winter, that these variations are due mainly to the effects of snow physical parameters and the cloud cover. The primary snow physical parameters
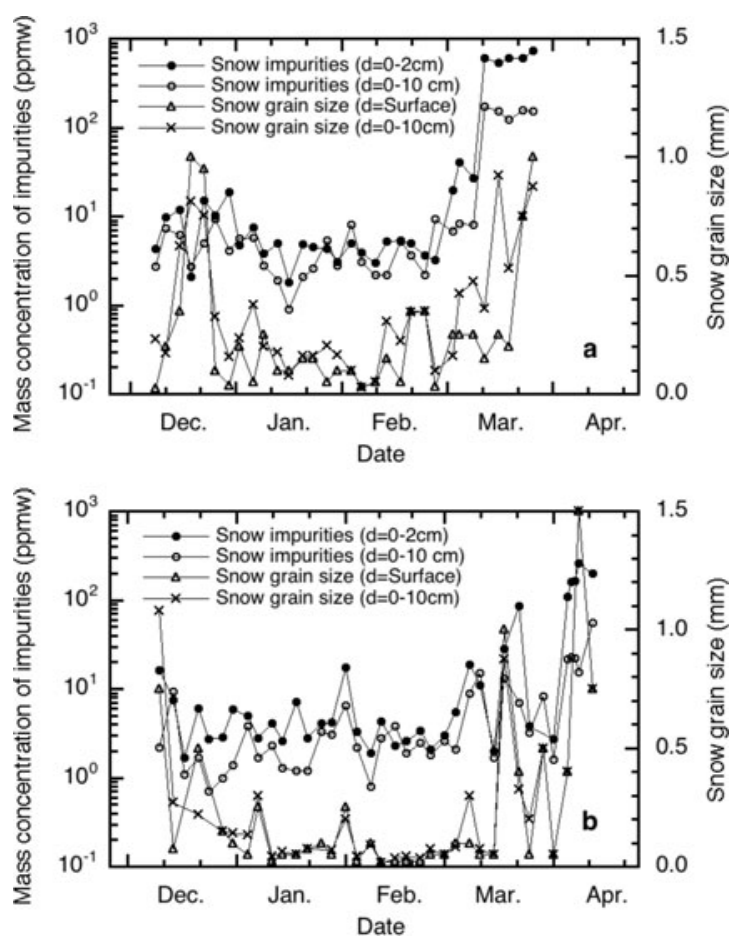

Fig. 3. Snow grain size measured from snow-pit work and mass concentrations of snow impurities measured from snow samples during the winters of 2003/04 (a) and 2004/05 (b). Each snow physical parameter was measured for the various snow layers, which are denoted by snow depth $d$ from snow surface. The definition of snow grain size is the same as for $r_{2}$ in Aoki and others (2003).

affecting the albedo are snow impurities (mainly for the visible region) and snow grain size (for the near-infrared region) (Warren and Wiscombe, 1980; Wiscombe and Warren, 1980). According to the theoretical simulation for cloud effects on snow albedo conducted by Aoki and others (1999), the shortwave albedo was increased by 0.04 $\left(\theta_{0}=66^{\circ}\right.$ at winter solstice $)-0.07\left(\theta_{0}=34^{\circ}\right.$ at snow-cover disappearance) by cloud cover for a snow grain radius of $0.05 \mathrm{~mm}$. This simulation includes both the effects of cloud cover, which changes the spectral distribution of incoming radiation and the sky-averaged incidence angle to a value larger than $\theta_{0}$, while snow albedo may still increase depending on cloud condition and snow grain size. Therefore, the short-term albedo variations would contain the effects of not only snow physical parameters, but also cloud cover.

During the melt season, the albedo decreased with snow depth. This tendency is remarkable for the near-infrared albedo. The visible albedo sometimes recovered to high values around 0.9 due to new snowfalls, but could not maintain this for a long period. During the melt season, both the snow grain size and the mass concentration of snow impurities increased significantly (Fig. 3) except for days when the surface was covered by new snow. Changes in these snow physical parameters reduce the albedo. The other factors affecting snow albedo are $\theta_{0}$, the snow depth and liquid water in the snow. During this period, the value of $\theta_{0}$ varies from $50.6^{\circ}$ (1 March) to $34.5^{\circ}$ (12 April) at the local solar noon (Fig. 2). The simulated shortwave albedo reduction due to a change of $\theta_{0}$ is $<0.02$ for a snow grain radius of $1 \mathrm{~mm}$ under a clear sky (Aoki and others, 1999), so this effect is not essential. Aoki and others (2006) 

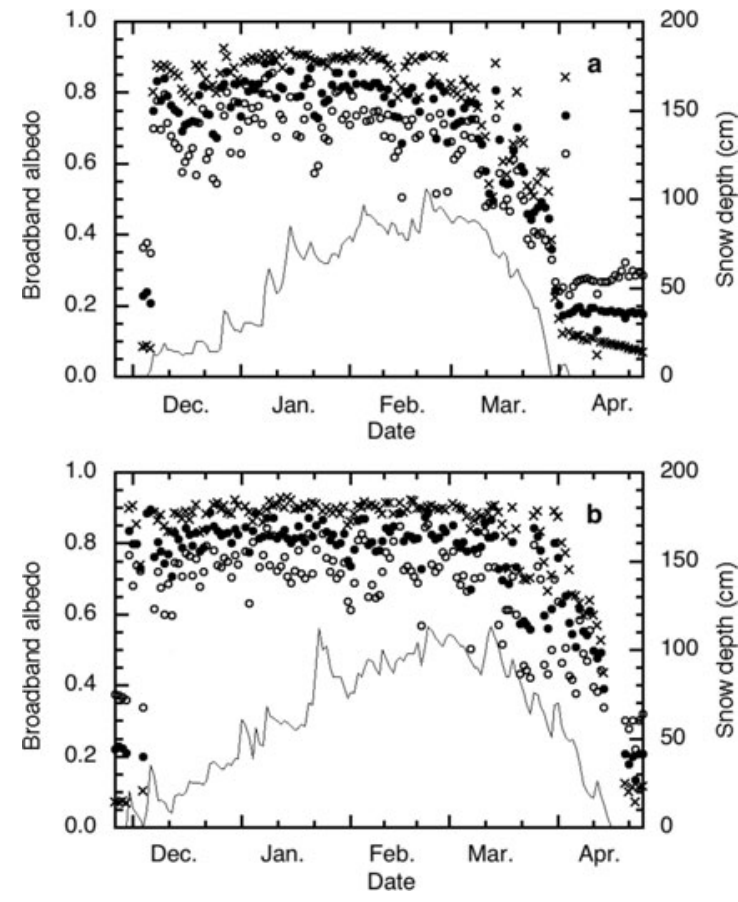

Fig. 4. Visible (crosses), shortwave (filled circles) and near-infrared (open circles) albedos averaged from 1131 to $1200 \mathrm{~h} \mathrm{LT}$, and snow depth, $d_{s}$ (solid curve), during the winters of 2003/04 (a) and $2004 / 05$ (b). Due to a data-logger malfunction, some data for $d_{\mathrm{s}}$ are missing for the entire period of the first winter and 18 March13 April 2005. The plotted $d_{\mathrm{s}}$ values for the missing periods were determined from snow-pit work, and the values for the days without snow-pit work were interpolated using data from SDMO.

explained, based on the data from the 2003/04 winter, that the effects of snow depth should appear during the last several days before the snow disappearance date, and that liquid water would enhance the effect of snow grain size on albedo reduction because increasing the liquid water could increase the optically equivalent snow grain size. These explanations are also plausible for the results from the 2004/05 winter. In the next subsection, we quantitatively examine the effects of snow grain size and impurities on the albedo based on comparisons with theoretically calculated albedos.

\section{Effects of the snow physical parameters on broadband albedos}

The relationships between broadband albedos and snow impurities for two different sampling layers are illustrated in Figure 5. The measured visible albedos, denoted by characters, clearly depend on the mass concentration of snow impurities for the cases of $d=0-2 \mathrm{~cm}$ and $d=0-10 \mathrm{~cm}$ (Fig. 5a). Curves illustrate the theoretically calculated maximum and minimum broadband albedos during the observation period for each of three different types of snow impurity models, using a radiative transfer model for the atmosphere-snow system (Aoki and others, 1999). In this model, each snow layer is assumed to be semiinfinite and homogeneous (the snow grain size and mass concentration of snow impurities have constant profiles in a snowpack). The maximum and minimum curves are determined from simulated albedos for all possible ranges of geometric conditions, sky conditions and the measured snow physical parameters during the observation period. A
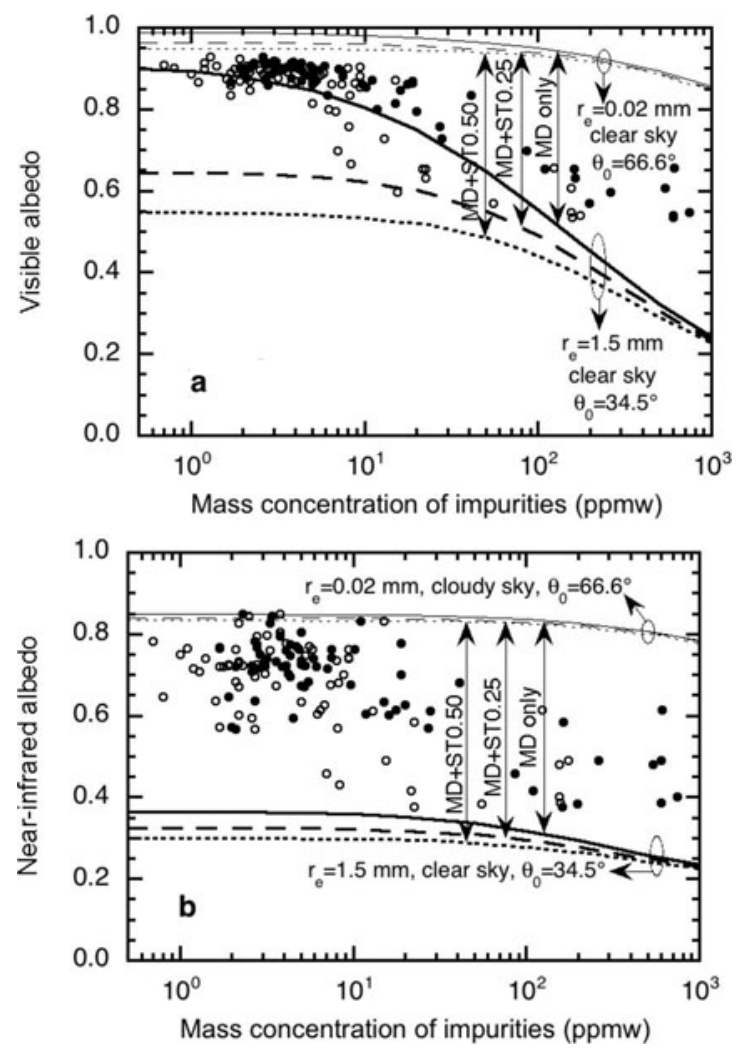

Fig. 5. Visible albedo (a) and near-infrared albedo (b) as a function of the mass concentration of snow impurities during the period 2003-05. Characters denote the measured albedos vs mass concentration of snow impurities measured for the snow surface (filled circles) and the snow layer from surface to $10 \mathrm{~cm}$ (open circles). Thin and thick curves indicate the theoretically predicted maximum and minimum albedos during the observation period using three types of snow impurity models: MD only, MD+ST0.25 and MD+ST0.50. The snow grain size $\left(r_{\mathrm{e}}\right)$, sky conditions (clear/ cloudy) and solar zenith angle $\left(\theta_{0}\right)$ corresponding to the maximum and minimum albedos were determined within the measured ranges of these parameters during the observation period.

detailed method to determine the maximum and minimum albedo is described in section 4.3 and the appendix of Aoki and others (2003). In the present study, the maximum albedo is expected for the smallest snow grain radius $(0.02 \mathrm{~mm})$, at the largest $\theta_{0}\left(66.6^{\circ}\right.$ on the winter solstice), under a clear sky (for the visible albedo) or cloudy sky (for the near-infrared albedo). The minimum albedo is expected for the largest snow grain radius $(1.5 \mathrm{~mm})$, at the smallest $\theta_{0}\left(34.5^{\circ}\right.$ on 12 April), under a clear sky. The smallest and largest values of snow grain size are the in situ measured minimum and maximum values during the two winters.

Since the optical properties of snow impurities are uncertain factors, we adapted the typical aerosol models in the same manner as Motoyoshi and others (2005), in which three types of aerosol (snow impurity) mixings from mineral dust (MD) and soot (ST) were assumed: (1) MD-only model (MD only), (2) MD with ST of 0.25 ppmw model (MD+ST0.25), and (3) MD with ST of 0.5 ppmw model (MD+ST0.50). For example, when mass concentration of snow impurities is 1 ppmw, the MD+ST0.25 model consists of soot of $0.25 \mathrm{ppmw}$ and dust of $0.75 \mathrm{ppmw}$. In these impurity models, light absorption is weakest for MD-only and strongest for MD+ST0.50. The optical properties for MD and ST were employed from the 'transport mode' of the 

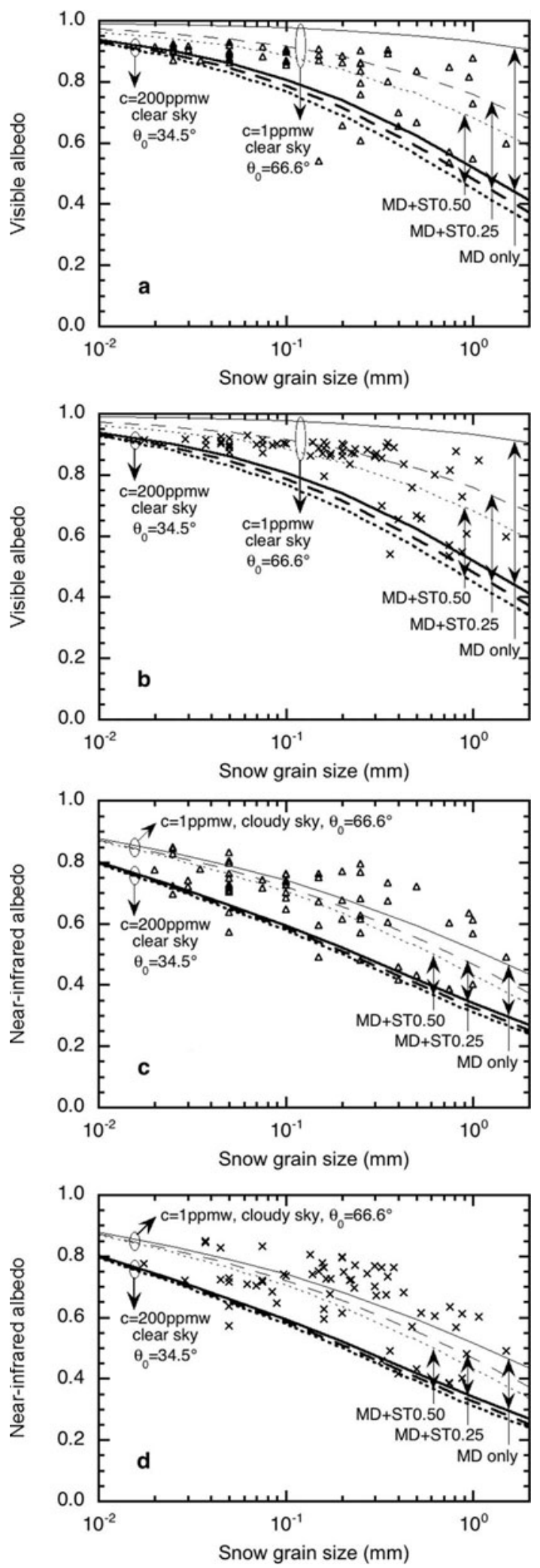

Fig. 6. Visible albedo $(a, b)$ and near-infrared albedo $(c, d)$ as a function of snow grain size during the period 2003-05. Characters denote measured albedos vs in situ measured snow grain sizes at the snow surface $(\mathrm{a}, \mathrm{c})$ and averaged over the snow layer from surface to $10 \mathrm{~cm}(\mathrm{~b}, \mathrm{~d})$. Thin and thick curves indicate the theoretically predicted maximum and minimum albedos during the observation period using three types of snow impurity models: MD only, MD+ST0.25 and MD+ST0.50. The mass concentration of snow impurities, $c$, sky conditions (clear/cloudy) and solar zenith angle, $\theta_{0}$, corresponding to the maximum and minimum albedos are determined within the measured ranges of these parameters during the observation period. mineral dust model and the soot model both compiled in the Optical Properties of Aerosols and Clouds (OPAC) database by Hess and others (1998).

In Figure 5, the range between the maximum and minimum albedo curves for each aerosol mixing type represents the possible variation of albedos. Although the range of the theoretically predicted visible albedo for the MD-only case takes values up to 0.99 for low concentrations of snow impurities (Fig. 5a), the measured visible albedos went up to 0.93 , which was recorded for new snow during the accumulation season. Major data points are distributed within the ranges for MD+ST0.25 or MD+ST0.50. Even the highest albedos are lower than the maximum albedo curve of $\mathrm{MD}+\mathrm{ST} 0.50$. These results suggest that the snow in Sapporo was contaminated not only with mineral dust but also with more absorptive soot.

On the other hand, the amount of information on snow impurities contained in the near-infrared albedo is not as great. As a result, the theoretically calculated near-infrared albedos do not differ remarkably among the three types of snow impurity models (Fig. 5b). Although the measured values of near-infrared albedos fall completely within the ranges of the theoretically predicted albedos, the measured values are distributed from the upper left to the lower right in the theoretically predicted ranges. This is because, in general, the measured snow impurity and snow grain size correlate to each other (Aoki and others, 2003).

The relationships between broadband albedos and snow grain size for two different snow layers are illustrated in Figure 6 . In the theoretical calculations, the maximum albedo is expected for low snow impurities ( 1 ppmw), at the largest $\theta_{0}$ $\left(66.6^{\circ}\right)$, under a clear sky (for the visible albedo) or a cloudy sky (for the near-infrared albedo). The minimum albedo is expected for high snow impurities (200 ppmw), at the smallest $\theta_{0}\left(34.5^{\circ}\right)$, under a clear sky. The low and high values for the mass concentration of snow impurities are not the minimum and maximum values, but the lower and upper values of the distribution group of impurity concentrations measured from snow samples for $d=0-10 \mathrm{~cm}$. The measured snow grain sizes plotted in Figure $6 \mathrm{a}$ and $\mathrm{c}$ are for the shallower snow layer ( $d=$ surface); Figure $6 b$ and $d$ are for the deeper layer $(d=0-10 \mathrm{~cm})$. The data points for $d=0-10 \mathrm{~cm}$ (Fig. $6 \mathrm{~b}$ and $\mathrm{d}$ ) shift in the direction of large grain size compared with those for $d=$ surface (Fig. 6a and c) because the measured snow grain sizes in the lower layer were larger than those for the surface as seen in Figure 3. For visible albedo (Fig. 6a and b), data points (measurements) outside the range of the theoretical curves for $d=0-10 \mathrm{~cm}$ are fewer than those for $d=$ surface, while the situation is reversed for the case of near-infrared albedo (Fig. 6c and d). This is because light absorption by ice (snow grains) is weaker in the visible wavelengths than in the near-infrared wavelengths. The visible albedo contains information on snow grain size in deeper snow layers, while the near-infrared albedo contains only information on the shallower layers. This phenomenon is confirmed by remote sensing of snow grain size (Tanikawa and others, 2002) and by theoretical study for vertical inhomogeneity of snow on spectral albedo (Zhou and others, 2003). In Figure 6c and d, some measured albedos where the measured snow grain size is $0.2-0.3 \mathrm{~mm}$ are distributed at higher values than the theoretical predictions (cloudy case). Before snow disappears, the snow depth can be very thin and spectral albedo of the grassland beneath the snow cover could play some role in snow surface albedo. 
However, the minimum snow depths before snow disappearance at which the measured albedos are plotted in Figure 6 were $39 \mathrm{~cm}$ in 2004 and $24 \mathrm{~cm}$ in 2005 . Thus, less effect of underlying surface would be expected. One possible reason is the assumption of an inappropriate cloud model (regarding cloud type and thickness) in the theoretical calculations.

\section{CONCLUSIONS}

Variations of the snow physical parameters and their effect on albedo were investigated from the data of radiation budget, meteorological components and frequent snow-pit work measured in Sapporo during two winters in 2003-05. Snow types observed in the accumulation season showed a significant contrast with those previously observed at Kitami, although the sites are located at a similar latitude and at a low altitude. Since the internal snow types would be affected by local climate conditions, the monitoring of snow types is important.

Measured snow grain sizes were on the order of $1.0 \mathrm{~mm}$ for granular snow and were one order of magnitude smaller for new snow and (lightly) compacted snow. The latter sizes are on the same order as, or larger than, those measured in Antarctica. Measured mass concentrations of snow impurities for snow layers of $d=0-2 \mathrm{~cm}$ and $d=0-10 \mathrm{~cm}$ were 2-8 and $0.7-8$ ppmw, respectively, during the accumulation season, and sometimes exceeded 100 ppmw during the melt season. Increases in both snow grain size and mass concentration of snow impurities contributed to a reduction in snow albedo.

The measured relationships between broadband albedos and the mass concentration of snow impurities agreed with the theoretically predicted relationship for the snow model assuming contamination not only with mineral dust but also with more absorptive soot. A similar comparison for the relationships between broadband albedos and snow grain size revealed that the visible albedo contains information on the snow grain size in deeper snow layers $(d=10 \mathrm{~cm})$, and that the near-infrared albedo contains information on only the top snow layer. This is because light absorption by ice (snow grains) is weaker in the visible wavelengths than in the near-infrared wavelengths.

\section{ACKNOWLEDGEMENTS}

We thank S. Kanamori, K. Konya, G. Yamazaki, N. Imanishi, S. Shishido, N. Tsubonuma, R. Kurosawa, N. Nagumo, T. Sakurai, Y. Sawada and S. Tsutaki at the Institute of Low Temperature Science of Hokkaido University for snow-pit work throughout two winters. This study was conducted as part of the Experimental Research Fund for Global Environment Conservation, supported by the Ministry of the Environment of Japan, and the ADEOS-II/GLI Cal/Val experiment, supported by the Japan Aerospace Exploration Agency (JAXA). This study was supported partly by a Grant for Joint Research Program of the Institute of Low Temperature Science, Hokkaido University.

\section{REFERENCES}

Aoki, T. and 6 others. 1998. Spectral albedo observations on the snow field at Barrow, Alaska. Polar Meteorol. Glaciol. 12, 1-9.
Aoki, T., T. Aoki, M. Fukabori and A. Uchiyama. 1999. Numerical simulation of the atmospheric effects on snow albedo with a multiple scattering radiative transfer model for the atmospheresnow system. J. Meteorol. Soc. Jpn, 77(2), 595-614.

Aoki, T., T. Aoki, M. Fukabori, A. Hachikubo, Y. Tachibana and F. Nishio. 2000. Effects of snow physical parameters on spectral albedo and bidirectional reflectance of snow surface. J. Geophys. Res., 105(D8), 10,219-10,236.

Aoki, T., A. Hachikubo and M. Hori. 2003. Effects of snow physical parameters on shortwave broadband albedos. J. Geophys. Res., 108(D19), 4616. (10.1029/2003JD003506.)

Aoki, T., H. Motoyoshi, Y. Kodama, T.J. Yasunari, K. Sugiura and H. Kobayashi. 2006. Atmospheric aerosol deposition on snow surfaces and its effect on albedo. Sci. Online Lett. Atmos. 2, 1316. (10.2151/sola.2006-004.)

Flanner, M.G. and C.S. Zender. 2006. Linking snowpack microphysics and albedo evolution. J. Geophys. Res., 111(D12), D12208. (10.1029/2005JD006834.)

Gay, M., M. Fily, C. Genthon, M. Frezzotti, H. Oerter and J.G. Winther. 2002. Snow grain-size measurements in Antarctica. J. Glaciol., 48(163), 527-535.

Hansen, J.E. and L. Nazarenko. 2004. Soot climate forcing via snow and ice albedos. Proc. Nat. Acad. Sci. USA (PNAS), 101(2), 423-428.

Hess, M., P. Koepke and I. Schult. 1998. Optical properties of aerosols and clouds: the software package OPAC. Bull. Am. Meteorol. Soc., 79(5), 831-844.

Hirashima, H., K. Nishimura, E. Baba, A. Hachikubo and M. Lehning. 2004. SNOWPACK model simulations for snow in Hokkaido, Japan. Ann. Glaciol., 38, 123-129.

Koch, D. and J. Hansen. 2005. Distant origins of Arctic black carbon: a Goddard Institute for Space Studies ModelE experiment. J. Geophys. Res., 110(D4), D04204. (10.1029/ 2004JD005296.)

Marshall, S. and R.J. Oglesby. 1994. An improved snow hydrology for GCMs. Part 1: Snow cover fraction, albedo, grain size, and age. Climate Dyn., 10(1-2), 21-37.

Motoyoshi, H., T. Aoki, M. Hori, O. Abe and S. Mochizuki. 2005. Possible effect of anthropogenic aerosol deposition on snow albedo reduction at Shinjo, Japan. J. Meteorol. Soc. Jpn, 83(A), 137-148.

Nolin, A.W. and A. Frei. 2001. Remote sensing of snow and characterization of snow albedo for climate simulations. In Beniston, M. and M. Verstraete, eds. Remote sensing and climate modelling: synergies and limitations. Dordrecht, etc., Kluwer Academic Publishers, 159-180.

Roesch, A., C. Schaaf and F. Gao. 2004. Use of ModerateResolution Imaging Spectroradiometer bidirectional reflectance distribution function products to enhance simulated surface albedos. J. Geophys. Res., 109(D12), D12105. (10.1029/ 2004JD004552.)

Tanikawa, T., T. Aoki and F. Nishio. 2002. Remote sensing of snow grain-size and impurities from Airborne Multispectral Scanner data using a snow bidirectional reflectance distribution function model. Ann. Glaciol., 34, 74-80.

Walden, V.P., S.G. Warren and E. Tuttle. 2003. Atmospheric ice crystals over the Antarctic Plateau in winter. J. Appl. Meteorol., 42(10), 1391-1405.

Warren, S.G. 1982. Optical properties of snow. Rev. Geophys. Space Phys., 20(1), 67-89.

Warren, S.G. and W.J. Wiscombe. 1980. A model for the spectral albedo of snow. II: Snow containing atmospheric aerosols. J. Atmos. Sci., 37(12), 2734-2745.

Wiscombe, W.J. and S.G. Warren. 1980. A model for the spectral albedo of snow. I. Pure snow. J. Atmos. Sci., 37(12), 2712-2733.

Zhou, X., S. Li and K. Stamnes. 2003. Effects of vertical inhomogeneity on snow spectral albedo and its implication for optical remote sensing of snow. J. Geophys. Res., 108(D23), 4738. (10.1029/2003JD003859.) 